\title{
e-government for all - Norm-critical perspectives and public values in digitalization
}

\author{
Elin Wihlborg \\ Linkoping University, \\ Sweden \\ elin.wihlborg@liu.se
}

\begin{abstract}
There are hopes that e-government will bring many benefits, including efficiency, democratization, participation, and emancipation of citizens. However, despite some evidence that supports these claims there are also cases that digitalization can exclude citizens and build new barriers. This is a special challenge for already disadvantaged groups falling outside the norms. In this study we approach the notion of a normcritical perspective in relation to e-government through a review of literature in combination with action research oriented workshops. From this we conclude that there is a need for more norm-critical perspectives in research on e-government, as most research today focuses on socio-economic digitaldivide issues. We also show that it is difficult for involved actors to see beyond the norms and be normcritical since the norms are embedded into the practices, which in this case, e-government has developed and used.
\end{abstract}

\section{Introduction}

There are hopes that e-government will bring many benefits such as increased efficiency, democratization, inclusion, participation and a common emancipation of citizens in the digital age [1-3]. E-government is formed on the common public values of public services and administration such as democracy, efficiency, and rule of law in particular in the more networked forms of government and society $[4,5]$. In such settings the flexibility of e-government appears to be attractive for adopting public services to personal needs relating to personal request. Since e-government often is seen as prolongation of new public governance $[6,7]$ it also carries certain public values such as customer-like focuses and market-like relations. However, the services are often designed with a notion of the stereotypical user and thus embedding an assembly of values based on the notion of the normal. Thereby the potential for e-government as a tool to
Karin Hedstrom

bro University, Sweden

arin.hedstrom@oru.se

\author{
Hannu Larsson \\ Örebro University, Sweden \\ hannu.larsson@oru.se
}

address social inequalities is lost in the normalization of the user. The importance of a more equal society addressing the complex and versatile demands of citizens is also highlighted in United Nation's (UN) set of sustainable development goals. It shows how equality and in practice norm-critical approaches can contribute to end poverty, protect the planet, and ensure prosperity for all [8]. E-government can thus play an important role in processes towards sustainable development including for instance the goals to "reduce inequalities" and to enhance "peace, justice and strong institutions" [8].

A key part of advanced e-government is to deliver integrated public e-services to citizens. Here it becomes critical to keep up governmental legitimacy and democracy by ensuring that all citizens have the means to access public services [3, 9]. This discussion on public values in government has been emphasized as a general line that needs to be addressed by research in e-government in order to ensure a good fit between technology and society [1]. There are also studies focusing on public core values within e-government in contexts such as elderly care services [10], or education and health care [11].

However, the lack of possibilities to access eservices, often called "digital divide" [12], has to include more than having the basic technical and literary competencies needed, which are the digital divide barriers commonly addressed in e-government research. It is also important that the e-services address other barriers for usage, such as language, age, disabilities, as well as different cultural and gender markers that are seen as grounds of discrimination. Previous e-government research generally adopts a quite narrow focus on the "normal" citizen that might even deepen the divides, with citizens risking to fall outside the services provided through e-government. This was also an issue raised among representatives from public sector organizations that we have met during our field work. We have thus identified a need to support processes of e-government development to include and build on a broader perspective of citizens. Questions of "normality" need to be in focus coupled with a critical reflection on who the citizen is, and how we view the citizen in order to ensure inclusion of 
everyone. This issue of diversity is particularly difficult to manage, as many public authorities need to meet the demands of a more diverse society at the same time. Here are also demands to rule egovernment by the law and to address a society that is “...fragmented and divided by gender, race, disability, class, location or religion [where the citizens] experiences with ICTs will vary enormously as will their opportunities to utilize it" [13].

Research on e-government as well as on digital divide issues has become more sophisticated, but, at the same time, less integrated. There is therefore a need to merge the fields of digital divide and egovernment in order to contribute to research as well as practice [14]. To address the digital divides of egovernment we need to take off from the notion of the complexity of the user. It is not always possible to develop e-government services based on a clear norm of who the typical user is. We have to be critical to such norms by applying a norm-critical perspective. Not least since the economic-poor or the 'informationpoor' are no more a homogeneous social phenomenon than their wealthier counterparts

This paper extends the notion of "digital divide" to include a norm-critical perspective $[15,16]$ that addresses aspects of accessibility other than what is traditional (i.e., technical and literary competencies). With norm-critical we refer to the effort to investigate the norms and normative assumptions that are at play [15]. Through a norm-critical perspective we will discuss concepts such as "normality” and, at the same time, uncover the hidden and for-granted assumptions about oneself and others. For those who belong to the normal, the need for a norm-critical perspective is usually not obvious, as are the consequences of not being norm-critical. Considering the role of governments, it is however of great importance that development of public services is developed using a norm-critical perspective in order to include all citizens, irrespective of age, ethnicity, religion or other beliefs, disability, sexual orientation, or transgender identity and expression [17]. This paper thus lies in the tradition of critical research where the purpose is to “achieve emancipatory social change” [18]. Also, it is important to reveal and take into consideration how different limiting structures are interrelated (i.e., intersectionality) [19].

\subsection{Aim of the paper}

This paper opens for and elaborates on a normcritical perspective in the field of e-government through a research overview and a design model of interactive workshops striving to enhance nonnormative approaches by extending professional competences. This paper has a two-folded aim. Firstly, we will elaborate on the meanings of norm-critical perspectives in relation to e-government through a research overview. Secondly, based upon a set of workshops, we will reflect upon the experiences of a workshop approach for norm-critical innovations in the context of e-government. Based on this aim the paper is guided by two research questions:

RQ1: How can a norm-critical perspective be understood in the e-government context?

RQ2: How can the workshop approach enhance the understanding of norm-critical perspectives in the governmental organizations by providing tools to unveil the main norms from a critical point of view?

\section{$1.2 \quad$ Outline of the paper}

The research questions will guide the structure of the paper. The theoretical framing of this analysis, presented in section two, is that e-government is translated in use and that it also translates meanings. The literature review of norm-critical perspectives in the field e-government is presented in the third section. In the fourth section we present how we have addressed these challenges through workshops based on an action-research approach. Finally, we conclude and open up the discussion for a more general approach on norm-critical perspectives in egovernment.

\section{A norm-critical perspective on e- government}

This section discusses our theoretical base in order to lay the foundation for the paper.

\subsection{A norm-critical approach}

A norm-critical perspective refers to the need of opening up for criticism to explicit and implicit norms $[15,19]$. This serves as a tool to probe into IS-practices in ways that differ from a purely management oriented perspective and instead understand or explain practices from perspectives that have previously been silent. In this paper, this is the citizen perspectives and the complexities inherit to this vast array of viewpoints. The purposes of applying a critical perspective to IS research is closely linked to practice; "Since the researcher's commitment to social change would enter into the mix when the critical lens is employed, the outcomes would not only contribute to theoretical insights but also to practice” [20]. Hence, applying a critical perspective opens up for researchers to take part in social change, which, in this study, is 
done directly through action research, discussed further in section four.

\subsection{Public values \& e-government}

All governmental activities relate to public values. In democratic states, the democratic governance of governmental activities is based on public core values [21]. Core values such as democracy, efficiency and rule of law guide public management and are translated into new technological and organizational settings [22].

This means that services provided by governmental agencies are distinct from market services, and as such, the qualities of the services need to be evaluated differently from basic market ideas that good quality is to fulfill or even exceed the demands of the customer four key aspects (access, equality, cohesiveness and legitimacy). Governmental services are distinguished and were shown to have specific consequences for design, management and quality of the services and other activities [23]. Firstly, they highlighted how the end-users' rights and access to services has to be considered. Secondly, equality is a key facet of democratic public services. Next, the elements of coerciveness are a unique feature of public services. Finally, the services have to be formed and delivered via legitimate processes [23]. These four key aspects can be reflection grounds for how norms are embedded into public services in general. Firstly, a norm-critical perspective has to stretch into each users' needs and rights. Secondly, equality is complex [24] but simply it means each and every user's right to meet a non-normative approach independently of their individual situation. The elements of coerciveness can be addressed by a non-normative and non-defensive approach if there is an openness and general respect for inequalities. If non-normative approaches are characterizing the public services, they will be experienced as legitimate.

\subsection{When the norm gets normative - The Swedish legislation on discrimination}

The Swedish constitution relies on clear expression of human rights as equal rights and opportunities. Thus there has been several forms of legislation on equal rights that, since 2009, have been combined into the comprehensive Discrimination Act [17]. The overall aim of the legislation is to enable authorities, single individuals, and other actors to contest actions that directly or indirectly violate the principle of the equal worth of all people. A national governmental agency, the Equality Ombudsman, is in charge of supervising other actors' compliance with the Act. In the
Discrimination Act, the grounds for discrimination are defined within seven subcategories; gender, gender identity or expression, ethnicity, religion or other beliefs, physical or mental disability, sexual orientation, and age. Discrimination on all of these grounds must be provided against, especially in times of political and global disturbance, in order to create a community that is open to change and that welcomes new members or minorities. Discrimination within these categories means that a person or group is being judged in terms of one or more of these grounds [25].

\subsection{A socio-technical setting}

In order to guarantee public values, there are limitations for when the values are leading to discrimination. Hereby, we open the conceptual meaning in the phase of interpretation, analysis, and writing to stretch beyond given categories. Herby we aimed to open for new ways of designing and using egovernment in line with action research for democracy [26]. We are including technological artifacts into a norm-critical discussion where the role of non-humans (the artifacts and even technical systems) is embedding public values into the socio-technical systems context [27].

\section{Searching for traces of norm-critical research - Our Research overview}

This section addresses the first part of the aim of the paper, which is a research overview. This section also presents the methods and material for the research overview and discusses two lines of argumentation. The first comes from research on public participation, coupled with an understanding of who the users/citizens are, and the second has to do with the notion of the digital divide.

\subsection{Methods and Material}

The purpose of this literature review was to find relevant research concerning inclusion/exclusion, marginalization, or alienation of citizens in egovernment. The main source of the literature search was the e-government reference library (EGRL) version 10.5, published January $25^{\text {th }} 2015$, a reference library comprising of 7237 e-government publications from peer-reviewed journals, conferences, and books [28]. The library covers the period from 1981 and consists of entries of publications in core egovernment journals, conferences, proceedings, and additional relevant publications from IS-journals. The library covers a vast majority of e-government 
research. Additional complementary searches were also done, as to find sources that might have been missed in the EGRL. An initial screening was done of 645 papers, which were browsed for relevance by looking at titles abstracts. A total of 49 papers were selected for more detailed scrutiny. Since the area of interest was broad and the main approach was exploratory, we made a broad search to cover a large scope of research that could possibly be relevant to norms, inclusion/exclusion, or barriers for egovernment. The search was structured after keywords and included (among others); citizen(s) in combination with digital divide, constraints, (in)equality, discrimination, capabilities, barriers, norms, and marginalization.

\subsection{The Users and Public participation}

The first aspect to grasp the notion of norm-critical perspectives is to address the user. In the literature on norm-critical perspectives is the broad and open interpretation of the user to include everyone and make everyone visible, and thus to go beyond the normative approach. Therefore our first focus in the research overview is on the user.

In e-government literature users are often seen as important actors in implementation phases. However, both the role of the users, as well as how users are seen and included, is more complex. In the more project oriented literature, users are for instance seen as stakeholders in the process of implementation, which indicates that projects should not be perceived as rational change processes, but as "emergent, dynamic and intertwined" [29]. Axelsson et al conclude that we need to consider that users, when being actively included in planning, can change perception by inclusion of important stakeholders and in particular how marginalized stakeholder-groups can become empowered by changes.

Performance assessment is commonly government-centric and focused on financial aspects while important dimensions like "customer perspective", ethics, sustainability, innovation and learning, and aesthetics need to be considered in norm-critical research. Barbosa et al suggest extending analyses of e-government users by also focusing on understanding the needs of citizens, service quality (offline as well as for portals), trust, and convenience of portals [30]. By including such dimensions public managers can get support in understanding the "social and technological context created by e-gov” [30]. Citizens should also be engaged in planning, as well as performance assessment [30], to strive for a citizen perspective.

Related to the need for understanding the citizens, there is a lack of research on how to understand the needs of senior citizens and design age-aware government services [31], which is one example of needed work against descrimination based on age. Others have also pointed out potential risks of excluding users from development of digital services, such as lack of user ownership, lack of system integration, overrun projects, illogical and poorly structured user interfaces, inaccurate mental models (for system use), as well as unexpected effects of the business processes [32]. These issues are raised with regard to public services in general, although they are applicable in discussing potential issues of excluding marginalized groups. If only certain types of users are represented in the planning of services, their norms, needs, and perspectives are the ones integrated into the design of e-government. By broadening the integration of users into design and development phases there are openings to be critical of such norms. Implicitly these studies point at potential norm-critical perspectives even if the concept is not used here.

The scope of the studies referred to above also relates to the potentially negative outcomes of not knowing the users of the planned services or portals. Helbig et al [14] show that one core issue for inclusion of citizens is the need to continuously pose questions about who the user is. Critical questions include: Who benefits? How are different groups influenced? What outcomes do different groups seek? And, how are others affected? This can be contrasted with the assumption of citizens as a homogenous group as there is a low understanding for "the determinants of demand" among citizens due to a poorly elaborated understanding of citizens as users, and also the asymmetry that it is the supply-side that often dictates which services that should be available, where users (citizens) are seen as potential adopters. Often, the result is low use. They also argue for the need to consider how public managers' assumptions about egovernment and digital divide issues influence the design [14]. Furthermore, poor understanding of users is problematic when working with target groups in “demand driven development”. Such categorizations can, however, be empty signifiers that hide differences between individuals who are included in the category. Thus, such approaches give practitioners little guidance for how to actually deal with such differences [33].

One case study on co-design highlights three perspectives: What is desired from a consumer perspective? What is possible from a technological perspective? And, what is viable from a business perspective? They argue that "Co-design is about finding the balance between what customers want, what is possible and what is viable" [34]. This is seen as a means to focus on including aspects that are 
important to the relevant user groups, as well as allowing for suitability and adaptability to the different users.

Linders [35] highlights different ways of allowing online participation of citizens in co-producing value of public sector activities, including; consultation, cogovernance, citizen reporting, crowd sourcing delivery of solutions to issues, self-service, transparency, as well as other aspects. However, he also highlights that further research is needed regarding the desirability and usefulness of such activities [35]. Loukis \& Wimmer [34] argue that electronic consultation requires relatively high levels of "sophistication" when done in a structured way. This might exclude less sophisticated users. However, this can indeed increase quality of input while decreasing the quantity if input [36]. This statement raises the issue of who is represented in such consultation, as we do not know who is being excluded from this process. Coproduction might be a suitable conceptual approach for inclusive e-services and policies. However, this would require us to elaborate on means of including not just citizens considered to be "sophisticated" and on not only using online channels.

\subsection{Digital divides}

The conceptualization of the digital divide has moved from a dichotomous have/have not to multidimensional models, including differences in usage levels and perspectives. However, this development has mainly focused on demographic and socioeconomic differences between adopters and nonadopters [40, 41]. The process of basic IT skills acquisition has been largely overlooked [42], as well as the need to consider cultural beliefs in relation to online interactions [43]. Skills and beliefs are particularly important to consider in the planning of inclusive services as a part of e-government.

There are also studies that show how the skills required to gain access to government services has increased with the emergence of e-government [44]. The social, emotional, and psychological barriers are important to consider when allowing for the inclusion of all citizens, as social and digital inclusion are interrelated. Digital and “offline” literacy have been highlighted as interrelated aspects that need to be addressed to avoid creating new barriers when adding technology [35]. It has been shown that "adaptation to the user's capabilities and available devices as well as physical and social environment” should play a major role in the planning of user interfaces [45].

Another way of framing exclusion/inclusion in relation to use of digital services is the capability approach, which has been used by Kleine et al [46] to understand the design of technologies for citizens. The basic assumption is that desirable development is something that supports what an individual has reason to value. Depending on an individual's capabilities and choices (for instance technical skills and lifegoals) the citizen may or may not use e-government. In order to avoid excluding users or decreasing the freedoms of non-users it is important to consider the values and preferences of the intended users before and during design [47]. The need to consider the effects on non-users is also highlighted by Letch \& Carrol [38] who show how mandatory use of eservices can further strengthen social, economic, and cultural influences that alienate already marginalized groups [48].

The infrastructural access is still critical for digital inclusion. Access to broadband and Wi-Fi is a critical aspect for inclusion and can open for new advance services for groups with special needs. These groups are easily forgotten and must be considered in each step of planning and development, when, for example, website accessibility and information is provided to support various groups. Special needs groups must be considered at all stages of a project and not become a one-time consideration, as well as be included in further revisions of policy and development. Accountability measures must be developed to avoid exclusion of people with disabilities [14]. Others have shown that the information needs among "underserved" people often are unarticulated or beyond their own comprehension, and could potentially result in further marginalization [37]. This has also been highlighted with regards to Wi-Fi access and website accessibility, as "special needs groups" might risk being treated as a one-time consideration in a project, rather than being considered throughout development [29]. Others have also shown that those in most need of government services might also be the ones with a lack of access to internet or capabilities to use the services. Hence, implementing e-services can broaden the gap and further increase exclusion. In order to include marginalized groups, services provided must be relevant to these specific user groups [38]. This might also be problematic as there are differences with regards to benefits and challenges for end-users, both those making up the majority and minority [39]. This focus of marginalized groups brings us back to the issue of the digital divide.

\subsection{Conclusions drawn from the research overview}

We can conclude that previous research related to a norm-critical perspective is uncommon. The same is true for literature where one critically addresses 
current assumptions and perspectives regarding citizens. Research on user/and or citizen participation instead commonly embraces a normative perspective where the user is seen as representing a specific stakeholder group in relation to e-government development. Questions on who the user is in relation to one-self or others with the purpose to uncover limiting structures or assumptions of users and "normality" are never addressed. Moreover, in the digital divide literature, the focus is usually on digital competence in combination with accessibility issues, giving less attention to other types of limiting structures.

\section{Interactive workshops to implement a norm-critical approach in e-government}

To address the more practical implications and elaborate on the meanings of norm-critical perspectives thereby achieving criticality, we arranged four action-research oriented workshops [49]. The key actors here were researchers, organization consultants, and representatives from public organizations that at the moment were working to develop new egovernment services. The consultancy focused on Lean models in public organizations. The four aspects, as discussed above, of access, equality, cohesiveness, and legitimacy were addressed through the workshop by being embedded into notions of e-government for all.

\subsection{Methods and Material}

The workshops were designed as a form of action research focusing on emancipation among the participants [26] and encouraging democratic implications. As researchers, we were active in the process of formulating issues to address, in line with the ambition of a norm-critical approach towards eservices. The role of the consultants was to facilitate and lead the workshops. The workshops had a specific focus on innovation, improved work processes, and user demands. We arranged four workshops in different regions in Sweden, inviting professionals from different municipalities. The participants from the municipalities were both those working in the ITmanagement unit and group leaders from different services, mainly social services and elderly care.

The workshops were approximately one working day in length, except for one that was set over two working days. The workshops started out with describing situations and challenges in each organization. By mixing the groups of participants, we challenged norms and praxis in the organizations. We also raised issues on common patterns related to general trends and models of public (e-)services. This approach opened for discussion on e-service development and how citizen inclusion could be enhanced. The third stage of the workshops was to focus on improved and potentially innovative tools and organizational processes. Participants from the same organization then got to work in small groups, supported by the researchers and consultants.

In total approximately 60 participants from 22 municipalities and regions were included. The role of us as researchers was double, in line with action research approaches $[50,51]$ since we both facilitated and analyzed the processes we were parts of. In addition, we were enhancing innovative practice for marginalized groups [52]. Hereby we applied a bottom-up approach as Lindberg [52] identified as critical to enhance inclusive innovation practices opening for more nuanced innovation models. Methodological challenges when addressing normcritical perspectives, beyond common practices of research, implementation, and innovation have been identified in other studies. Henry et al [53] claim in relation to a norm-critical approach that scholars must develop the methodological repertoire to engage with post-structural feminist approaches. This may require a radical move towards more innovative, in-depth qualitative methodologies. Here, where gender is just one of several perspectives, we aimed to grasp new aspects and strive to go beyond the (post) structures.

\subsection{Keeping the discussions on track - Solving problems by including everyone}

The design suggestions that arose from the workshops had a broad variety, based on the participants' various daily practices and plans for eservice development. Hence the workshop leader had to keep the discussions on track and bring up common issues to be discussed with regards to how citizens in general or specific types of users were viewed. Through the workshops it became obvious that a key for how innovations were framed was the way municipal professionals addressed and talked about the users of public services and, in particular, their use of public e-services and how citizens were or were not a part of planning and development. By using a normcritical perspective, pointing to what was left out of these plans and definitions, it became clear that predefined views of the intended users existed. Especially a clear view of what was considered to be normal in certain cases. We hence contributed to these discussions by re-framing the issues discussed with regard to a broader range of possible situations or perspectives. The norm-critical approach was practically used in order to question and enrich, the 
discussions. We encouraged participants to enhance and develop an awareness of tacit as well as explicit norms in current and suggested services. One of the main challenges for participants was to assume alternative perspectives in order to become aware of how formulations, design choices, and perspectives can be excluding. When specific questions were raised the participants elaborated on how good practices by necessity have to be individualized, and therefore also norm-critical. For instance, participants raised issues of inclusion in accessing e-services (physically as well as cognitively) as well as excluding aspects that might even be enhanced by moving from face-to-face meetings to e-services. One key insight among participants thus was that what might be enabling for some users could be problematic for others.

The workshop approach gave rise to issues with regard to a vast array of areas, including design and uptake of services to the potentially negative effects of such changes. This was made possible by the actionoriented approach where the workshop-leader, practitioner, and researcher-participants were all included in the discussions.

As a complement to the workshops and to extend the interpretations of norm-critical perspectives, we conducted a one-hour focus group interview [54]. The interview approach was unstructured and conversational in style. This was performed with staff at an organization working with supportive employment for people that, due to illness or disabilities, have problems establishing themselves on the job market. The aim was to elaborate on benefits and challenges of people with such obstacles using eservices and get insight into their experiences, as well as to reflect upon the lessons learned through the workshops. Since this organization focused on users that commonly fall outside the "norms", they had a high awareness of a norm-critical perspective. Admittedly, their specific focus on disadvantaged groups within the labor market limits the more general implications on equality, access, and legitimacy, but the main lesson from this interview is that awareness of non-normative approaches can be developed and embedded into daily practices. The non-normative approach became the norm of the organization.

\subsection{Bringing it back home - Implications from the workshops}

During the workshops the participants were positive and expressed that they felt empowered to incorporate norm-critical thinking into their future work. The aim to extend their professional competences by initiating norm-critical approaches was seen as beneficial. Through follow-up surveys after the workshops we saw that practical situations in their organizations came to hamper the implementation of ideas, despite an initial enthusiasm [22][55]. In the follow up survey the participants gave arguments as (our translation and editing of survey responses):

- We have not found any project that fits into this approach of e-government for all

- $\quad$ Other projects have been prioritized

- We are waiting some time with e-government issues, since it is difficult when you are the only person with this education [referring to our workshop]

- We made a model for these issues, but it was too complex and has to be more simple to be included in public procurement of new egovernment applications

One main obstacle was the perception that local governments are "slow movers" and that the attendees of the workshops lack mandate to "bring the issues home”. In line with Pollitt's study [22] on implementation of new technologies, like egovernment, such processes are often constrained by change-resistant institutional arrangements [55]. In these cases, the inspiration and enthusiasm among the participants was not enough to make sustainable changes in their home organizations. This despite the organizations already having to follow national legislation on discrimination.

Taken together this indicates that the participants in the workshops were mediators for norm-criticism [56]. However, their recourses and action spaces to make such changes were limited. Hopefully their new competences on non-normative approaches and egovernment may still open up for changes later on.

\section{A norm-critical perspective in theory and practice - Concluding remarks}

By elaborating on norm-critical perspectives in research on e-government we have shown the potential to extend the common focuses on socio-economic digital-divide issues. However, it is problematic to see beyond the norms that are embedded within the practices which e-government is developed and used. Thus we have to further translate and develop the norm-critical perspective into the fields of egovernment. In particular, there are risks that new egovernment applications may embed, enhance, or even create new social divides along with the digital divides. Based on these overall conclusions we will point at two specific design implications. Firstly, the need to challenge the notions of designing for "everyone" or representative groups. In design processes this may be made not by asking traditional 
questions of who the user is [50], but rather what are the key aspects of the user of public services without relating to any norms. Impartiality of public services, like equal treatment and access, can be developed to be even more equal when the grounds of discrimination are hidden by the e-interface. How can we find out demands of the users without being biased by specific interests or our own norms? Such issues indeed require a norm-critical approach.

The second design implication, based on the broader notion of the user as the common perspective of the citizen, is the contextualization of the egovernment services. There is a need to apply a high level of flexibility in the framing of services. There is also a need to be critical in regard to the norms embedded within the context in which the egovernment services are in use.

Research as well as practice on inclusive and nonnormative e-government may be addressed along three lines. Firstly, to highlight that governmental activities are about public values. We have to be aware of the power of e-government when it comes to carrying and communicating public values. Secondly, there are implicit and explicit values embedded into the design and use of e-government applications that are already in use. Thirdly, there is the task to formulate design implications that avoids new services from being

\section{References}

[1] F. Bannister and R. Connolly, "ICT, public values and transformative government: A framework and programme for research”, Government Information Quarterly, 2014, 31(1), pp. 119-128.

[2] A.J. Meijer, F. Bannister, and M. Theaens, "ICT, public administration and democracy in the coming decade", Information Polity, 2013, 17(3-4), pp. 201-207.

[3] A. Cordella and C.M. Bonina, "A public value perspective for ICT enabled public sector reforms: A theoretical reflection”, Government Information Quarterly, 2012, 29(4), pp. 512-520.

[4] B.G. Peters and J. Pierre, "Governance without government? Rethinking public administration.”, Journal of Public Administration Research and Theory, 1998, 8(2), pp. 223-243.

[5] G. Stoker, "Public value management a new narrative for networked governance?”, American Review of Public Administration, 2006, 36(1), pp. 41-47.

[6] A. Cordella, "E-government: towards the ebureaucratic form?”, Journal of information technology, 2007, 22(3), pp. 265-274. formed on biased and normative assumptions. Our action research workshop approach can be seen as an initial step in such a process as a means to highlight and question assumptions while in the early stages of planning the (re)design of such e-services. During our workshops we visualized and conceptualized the consequences that a lack of a norm-critical perspective could have for e-government applications. This made it possible for the participants to achieve a critical perspective towards their own views. This combination of a critical perspective and action research could be called critical action research. In future studies, we plan and encourage others to further elaborate on a more hands-on list of such criteria to be useful for practitioners. Another important and interesting line of research would be to further develop this "critical action research" approach.

We argue for the need of more research on egovernment with a norm-critical perspective to open up for new practices. The ambition is not just to build digital bridges over social divides, but to identify, challenge, and critically address how e-government tools can be used to bridge digital as well as social divides. Such processes are pivotal for a more inclusive society that is globally seen as the way forward to one which is more sustainable.

[7] P. Dunleavy, et al., "New public management is dead-long live digital-era governance”, Journal of public administration research and theory, 2006, 16(3), pp. 467494.

[8] UN. Sustainable Development Goals. 17 Goals to transform our world. 2016 [Acess 2016-06-15]; Available from:http://www.un.org/sustainabledevelopment/sustainabl e-development-goals/.

[9] H. Larsson and Å. Grönlund, "Sustainable eGovernance? Practices, problems and beliefs about the future in Swedish eGov practice”, Government Information Quarterly, 2016, 33(1), pp. 105-114.

[10] K. Hedström, "The values of IT in elderly care", Information Technology \& People, 2007, 20(1), pp. 72-84.

[11] K. Hedström, et al., "Constructing identities professional use of eID in public organisations", Transforming Government: People, Process and Policy, 2015, 9(2), pp. 143-158.

[12] P. Norris, Digital divide: Civic engagement, information poverty, and the Internet worldwide, Cambridge university press, 2001. 
[13] B.D. Loader, Cyberspace Divide: Equality, Agency and Policy in the Information Society, Routledge, 1998.

[14] N. Helbig, J.R. Gil-Garcia, and E. Ferro, "Understanding the complexity of electronic government: Implications from the digital divide literature", Government Information Quarterly, 2009, 26(1), pp. 89-97.

[15] Lundmark, S, Normkar, M and M. Räsänen, Exploring norm-critial design in online youth conseling, In 1st Intl. Workshop on Values in Design - Building Bridges between RE, HCI and ETHICS, Lisbon, Portugal, 2011.

[16] J. Bromseth and F. Sörensdotter, R. Norm-critical pedagogy. Gender Studies Education and Pedagogy, In Gender Studies Education and Pedagogy, Swedish Secreatiat for Gender Studies, 2014.

[17] Swedish Government, Discrimination Act, 2008:567.

[18] D. Cecez-Kecmanovic, "Basic assumptions of the critical research perspectives in information systems", Handbook of critical information systems research. Theory and application, D. Howdraft, D and E. Trauth (eds.), Edward Elgar, 2005.

[19] N. Lykke, Feminist studies: A guide to intersectional theory, methodology and writing, Routledge, 2010.

[20] D. Howcroft and E.M. Trauth, "The implications of a critical agenda in gender and IS research", Information Systems Journal, 2008, 18(2), pp. 185-202.

[21] R. Box, Public Service Values, M.E. Sharpe, 2014.

[22] C. Pollitt, New perspectives on public services: place and technology, Oxford University Press, 2012.

[23] M. Elg, E. Wihlborg, and M. Örnerheim, "Public quality - for whom and how? Integrating public core values with quality management”, Total Quality Management \& Business Excellence, 2015, pp. 1-11.

[24] M. Lipsky, Street-Level Bureaucracy: The Dilemmas of the Individual in Public Service, Russell Sage Foundation, 1983.

[25] C. Asberg and M. Ronnblom, (eds.), Debates in Nordic Gender Studies: Differences Within, Routledge, 2016.

[26] E. Gunnarsson, et al., Action Research for Democracy: New Ideas and Perspectives from Scandinavia, Routledge, 2015.

[27] S. Woolgar and D. Neyland, Mundane governance: Ontology \& accountability, Oxford University Press, 2013.
[28] H.J. Scholl. E-Government Reference Library (EGRL) version 10.5. 2015 [cited 2015 March 30]; Available from: http://tinyurl.com/d5j78px.

[29] R. Zambrano, "E-Governance and Development, Service Delivery to Empower the Poor", International Journal of Electronic Government Research, 2008, 4(2), pp. $1-11$.

[30] A. Dugdale, et al., “Accessing e-government: challenges for citizens and organizations”, International Review of Administrative Sciences, 2005, 71(1), pp. 109118.

[31] K. Mervyn, A. Simon, and D.K. Allen, "Digital inclusion and social inclusion: a tale of two cities.", Information, Communication \& Society, 2014, 17(9), pp. 1086-1104.

[32] L. Nakamura and P. Chow-White, Race after the Internet, New York, Routledge, 2012.

[33] K.L. Gidlund and J. Sefyrin, "Problematizing the Participatory Subject in Demands Driven Development of Public Sector", Electronic Government and Electronic Participation, M. Janssen (ed.), 2014.

[34] E. Loukis and M. Wimmer, “A Multi-Method Evaluation of Different Models of Structured Electronic Consultation on Government Policies", Information Systems Management, 2012, 29(4), pp. 284-294.

[35] D. Linders, We-Government: an anatomy of citizen coproduction in the information age, $12^{\text {th }}$ Annual International Conference on Digital Government Research (dg.o 2011), College Park, MD, ACM, 2011.

[36] K. Fielden and P. Malcolm, "E-government in New Zealand: Local Governments, Digital Divides and the National Digital Strategy", Comparative E-Government, 2010, 25, pp. 505-524.

[37] C. Folkerd and G. Spinelli, "User exclusion and fragmented requirements capture in publicly-funded IS projects”, Transforming Government: People, Process and Policy, 2009, 6(1), pp. 32-49.

[38] N. Letch and J. Carroll. Integrated E-Government Systems: Unintended Impacts for those at the Margins, $15^{\text {th }}$ European Conference on Information Systems, 2007.

[39] J.C. Sipior and B.T. Ward, "Bridging the Digital Divide for e-Government inclusion: A United States Case Study”, Electronic Journal of e-Government, 2005, 3(3), pp. 137146.

[40] E. Sánchez-Nielsen and C. Martín-Vázquez. Exploring How the Appreciative Inquiry Model can Vitalize the Online 
Citizen Debate, $13^{\text {th }}$ European Conference on eGovernment, 2013.

[41] C. de Caluwe, P. Verdegem, and W. Van Dooren, "The digital divide and/in e-government: a catch-22?” Tijdschrift Voor Communicatiewetenschap, 2012, 40(1).

[42] G. Calvary, et al., "Envisioning Advanced User Interfaces for E-Government Applications: A Case Study”, Practical Studies in E-Government: Best Practices from around the World, 2011, pp. 205-228.

[43] S. Scherer, et al., "Enabling eParticipation of the Youth in the Public Debate on Legislation in Austria: A Critical Reflection”, Electronic Participation: Proceedings of the $1^{\text {st }}$ IFIP WG 8.5 International Conference, ePart 2009, A. Macintosh and E. Tambouris, (eds.) 2009, pp. 151-162.

[44] A.F. Barbosa, M. Pozzebon, and E.H. Diniz, "Rethinking E-Government Performance Assessment from a Citizen Perspective”, Public Administration, 2013, 91(3), pp. 744-762.

[45] J. Harambam, S. Aupers, and D. Houtman, "The Contentious Gap: From digital divide to cultural beliefs about online interactions”, Information Communication \& Society, 2013, 16(7), pp. 1093-1114.

[46] D. Kleine, A. Light and M.J. Montero, "Signifiers of the life we value? - considering human development, technologies and Fair Trade from the perspective of the capabilities approach", Information Technology for Development, 2012, 18(1), pp. 42-60.

[47] V. Weerakkody, et al., "Conceptualizing E-Inclusion in Europe: An Explanatory Study”, Information Systems Management, 2012, 29(4), pp. 305-320.
[48] B. Niehaves, "Iceberg ahead: On electronic government research and societal aging”, Government Information Quarterly, 2011, 28(3), pp. 310-319.

[49] R. Baskerville and M.D. Myers, "Special issue on action research in information systems: making is research relevant to practice. Foreword”, MIS Q., 2004, 28(3), pp. 329-335.

[50] K. Axelsson, U. Melin, and I. Lindgren, "Exploring the importance of citizen participation and involvement in egovernment projects: Practice, incentives, and organization”, Transforming Government: People, Process and Policy, 2010, 4(4), pp. 299-321.

[51] U. Melin and K. Axelsson, "Action in Action Research - Illustrations of What, Who, Why, Where, and When from an E-Government Project" Electronic Government: $6^{\text {th }}$ International Conference, 2007.

[52] M. Lindberg, "From exclusion to inclusion in public innovation support? Innovative practices in bottom-up networks", Scandinavian Journal of Public Administration, 2014, 18(4), pp. 91-107.

[53] C. Henry, L. Foss, and H. Ahl, "Gender and entrepreneurship research: A review of methodological approaches”, International Small Business Journal 2015, 34(3), pp. 217-241.

[54] A. Bryman, Social Research Methods, Oxford University, 2004.

[55] J.G. March and J.P. Olsen, Rediscovering Institutions: The Organizational Basis of Politics, 1989, The Free Press.

[56] E. Wihlborg and K. Söderholm, "Mediators in action: Organizing sociotechnical system change", Technology in Society, 2013, 35(4), pp. 267-275. 